Gynecologic and

Obstetric Investigation

\title{
Early Intensive Obstetric and Medical Nutrition Care Is Associated with Decreased Prepregnancy Obesity Impact on Perinatal Outcomes
}

\author{
Enrique Reyes $^{a} \quad$ Nayeli Martínez $^{\mathrm{b}} \quad$ Adalberto Parra $^{\mathrm{a}} \quad$ Alfredo Castillo-Mora $^{\mathrm{a}}$ \\ Carlos Ortega-González ${ }^{\mathrm{a}}$ \\ Departments of andocrinology and ${ }^{\mathrm{b}}$ Gynecology and Obstetrics, Instituto Nacional de Perinatología Isidro \\ Espinosa de los Reyes, México City, México
}

\section{Key Words}

Gestational diabetes mellitus - Medical-nutrition prenatal

care $\cdot$ Pregestational obesity $\cdot$ Maternal and perinatal

outcomes

\begin{abstract}
Background/Aims: To compare the gestational weight gain and adverse perinatal outcomes in urban Mexican women with prepregnancy overweight or obesity, under an early intensive obstetric and nutrition program versus women with prepregnancy normal weight. Methods: A cohort of 546 pregnant women with prepregnancy normal weight ( $\mathrm{n}=$ 201 , NW), overweight ( $n=171, \mathrm{OW}$ ) or obesity ( $n=174, O B)$, $\leq 13$ weeks of gestation and a singleton pregnancy. $O W$ and OB groups were under early intensive obstetric and nutritional care and NW group was under routine prenatal care. Miscarriage, hypertensive disorders, premature rupture of membranes, preterm birth, stillbirth, gestational diabetes mellitus (GDM) and large- or small-for-gestational-age newborns, were compared between groups. Results: Weight gain was smaller in OB than in OW or NW (mean \pm SD): 6.1 $\pm 4.4,9.5 \pm 5.1,10.3 \pm 5.4 \mathrm{~kg}$, respectively $(p<0.001)$. OB women had the highest frequency of GDM ( $p<0.001)$, lack of spontaneous labor $(p<0.001)$ and preeclampsia $(p<$ 0.001 ), but no other between-group differences existed.
\end{abstract} Conclusion: Early intensive medical-nutrition prenatal care

\section{KARGER}

Fax +4161306 1234

E-Mail karger@karger.ch

www.karger.com
(C) 2011 S. Karger AG, Basel

0378-7346/12/0731-0075\$38.00/0

Accessible online at:

www.karger.com/goi and adequate gestational weight gain may contribute to decreasing most maternal and newborn adverse outcomes associated with prepregnancy overweight or obesity.

Copyright $\odot 2011$ S. Karger AG, Basel

\section{Introduction}

According to the World Health Organization (WHO), there are 400 million obese people in the World [1] and in México 60-70\% of women of reproductive age are either overweight or obese [2], which means that over half of them will become pregnant with overweight of variable degree.

Numerous retrospective and prospective studies have clearly demonstrated that obesity is an important pregnancy factor which increases maternal, fetal and perinatal morbidity, i.e. Cesarean delivery, gestational diabetes mellitus (GDM), hypertensive disorders including preeclampsia, abortions, premature rupture of membranes, stillbirth, early neonatal death, macrosomia and major congenital malformations [3-7].

Some studies have analyzed the independent effects of obesity on pregnancy outcomes in glucose-tolerant Caucasian women $[3,5,6]$, but few in Hispanic women who have a greater risk for GDM $[8,9]$ among other morbidities. 
The Institute of Medicine (IOM) recommends that gestational weight gain goals should be modified according to prepregnancy body mass index (BMI), which could result in better maternal and infant outcomes [10]. Recently, the IOM suggested the total gestational weight gain during pregnancy should be 12.7-18.1 kg for BMI $<18.5,11.3-15.8 \mathrm{~kg}$ for BMI 18.5-24.9, $6.8-11.3 \mathrm{~kg}$ for BMI 25-29.9, and 4.9-9 kg for BMI $\geq 30$. However, few studies have evaluated the impact of interventions to diminish weight gain during gestation on perinatal outcomes in Latin American women with overweight or obesity.

We aimed to compare the gestational weight gain and adverse perinatal outcomes both maternal and in the newborn in urban Mexican women with prepregnancy overweight or obesity without any concomitant disease under an early intensive obstetric and nutrition program versus women with prepregnancy normal weight under routine hospital prenatal care, attending a third-level medical institution.

\section{Material and Methods}

\section{Research Design and Study Population}

The National Institute of Perinatology is one of the main reference hospitals for gynecologic and obstetric health problems in Mexico. Our Institution attends mainly high-risk pregnancies, usually complicated by concomitant diseases.

We included 711 consecutive women attending for prenatal care to our institution from January 2007 to December 2008 with an uncomplicated pregnancy and $\leq 13$ weeks of gestation, but 165 women were excluded because they did not fulfill the inclusion criteria. Thus, the present report represents a historic cohort study of 546 consecutive Mexican low- and middle-class urban pregnant women with prepregnancy normal body weight, overweight or obesity. The protocol was approved by the Internal Review Board.

The inclusion criteria was gestational age $\leq 13$ weeks, a singleton pregnancy, without previous history of GDM or any other concomitant diseases, such as type 2 diabetes mellitus, pre-pregnancy hypertension, renal, immunologic or hepatic diseases, and planning to receive prenatal care and to have the resolution of their pregnancy at our institution.

The mother's self-reported pregestational body weight was confirmed at their first obstetric visit ( $\leq 13$ weeks of gestation) and their height measured to the nearest $\pm 0.1 \mathrm{~cm}$. Pregestational BMI was calculated as: weight $(\mathrm{kg}) /$ height $\left(\mathrm{m}^{2}\right)$. Women were divided into 3 groups according to their pregestational BMI: normal weight (NW, $\mathrm{n}=201)$ BMI 18.5-24.9, overweight (OW, $\mathrm{n}=171$ ) BMI 25.0-29.9, and obese $(\mathrm{OB}, \mathrm{n}=174) \mathrm{BMI} \geq 30$.

\section{Procedure}

Both the OW and the OB groups received intensive obstetric care and were included in a medical-nutrition program which has been published in detail elsewhere [8]. In brief, it consists of: (a) Monthly obstetric visits up to 30 weeks of gestation, afterwards biweekly up to 36 weeks of gestation and, thereafter, every week until the end of pregnancy. At the first obstetric visit $(\leq 13$ weeks of pregnancy) all women had a complete blood count analysis, determinations of serum glucose, urea, uric acid, creatinine, VDRL and HIV tests and urinalysis. An abdominal ultrasound was performed each trimester. Maternal weight was recorded at each visit and weight gain assessed according to our institution guidelines [11]. At each obstetric visit the obstetrician reinforced information concerning the maternal and fetal risks of obesity and excessive weight gain during pregnancy.

(b) Both OW and OB women initially received nutrition assessment and intervention within 2 weeks after admission to prenatal care with a balanced diet at $25 \mathrm{kcal} / \mathrm{kg}$ of ideal body weight for gestational age [8] never less than $1,500 \mathrm{kcal}$ with $45-48 \%$ of total energy as complex carbohydrates, $20-21 \%$ protein and $30-$ $32 \%$ lipids. In NW, the routine hospital prenatal care did not include nutrition assessment, but only specific information concerning the maternal weight gain during pregnancy; however, if weight gain was excessive NW women were immediately referred to a dietitian for nutrition assessment. In OW and OB the total energy intake was modified according to the progression of pregnancy at 4-week intervals, but if excessive, patients were immediately scheduled for a new visit with the dietitian. Diet was assessed monthly with multiple pass 24 -hour recalls as previously described in detail.

(c) Our institution advocated and provided universal two-step screening method for GDM at $\geq 14$ weeks of gestation. If the initial $50 \mathrm{~g}-1$ h glucose challenge test (GCT) was $<7.2 \mathrm{mmol} / \mathrm{l}$, it was repeated at $24-28$ weeks, but if $\geq 7.2 \mathrm{mmol} / \mathrm{l}$, a $100 \mathrm{~g}-3 \mathrm{~h}$ oral glucose tolerance test (OGTT) was performed within 2 weeks and GDM diagnosed with 2 or more abnormal values according to the American Diabetes Association guidelines [12]: fasting $\geq 5.3$ $\mathrm{mmol} / \mathrm{l}, 1 \mathrm{~h} \geq 10 \mathrm{mmol} / \mathrm{l}, 2 \mathrm{~h} \geq 8.6 \mathrm{mmol} / \mathrm{l}$ and $3 \mathrm{~h} \geq 7.8 \mathrm{mmol} / \mathrm{l}$.

(d) When GDM was diagnosed, patients were immediately referred to the endocrinologist who was responsible to reinforce nutrition assessment and prescribe human insulin (intermediateacting or NPH and rapid-acting or short-acting [regular] twice a day or in some cases, intermediate-acting or NPH human insulin, twice a day plus prandial rapid-acting insulin analogs) as needed to meet biweekly serum glucose goals (fasting $\leq 5.3 \mathrm{mmol} / \mathrm{l}$ and $1 \mathrm{~h}$ postprandial $\leq 7.8 \mathrm{mmol} / \mathrm{l})$.

\section{Sample Size}

Based on the proportion of large for gestational age of $6 \%$ in normal weight women, in order to find a minimum difference of $10 \%$ between normal and obese women, with a beta error of 0.10 and alpha of 0.05 , we calculated the sample size to be 168 women per group. Additionally, this sample size was adequately powered to find the double risk for GDM, miscarriage, preterm delivery, preeclampsia, cesarean delivery and lack of spontaneous labor.

\section{Outcome Variables}

Maternal and newborn outcomes comprised miscarriage (defined by loss of pregnancy before 20 weeks of gestation), GDM, premature rupture of membranes, preterm birth ( $<37$ weeks' gestation), gestational hypertension, preeclampsia [13], spontaneous labor, cesarean delivery, puerperium complications (including: dehiscence or infection of surgical wound, endometritis, deep vein thrombosis and febrile morbidity), gestational age at deliv- 
Table 1. Demographic characteristic of the women studied and their newborns ${ }^{\mathrm{a}}$

\begin{tabular}{lccc}
\hline Characteristics & $\begin{array}{l}\text { Normal weight: NW } \\
(\mathrm{n}=201)\end{array}$ & $\begin{array}{l}\text { Overweight: OW } \\
(\mathrm{n}=171)\end{array}$ & $\begin{array}{l}\text { Obesity: OB } \\
(\mathrm{n}=174)\end{array}$ \\
\hline At admission & $27.03 \pm 8.5$ & $30.5 \pm 7.3^{*}$ & $31.2 \pm 6.1^{\dagger}$ \\
$\quad$ Age, years & $10.6 \pm 1.6$ & $11.1 \pm 1.8$ & $11 \pm 1.7$ \\
Gestational age, weeks & $54.4 \pm 5.9$ & $66.1 \pm 6.4^{*}$ & $78.7 \pm 8^{\dagger, \S}$ \\
Body weight, kg & $22.3 \pm 1.6$ & $27 \pm 1.4^{*}$ & $32.8 \pm 2.5^{\dagger, \S}$ \\
Body mass index & $88(43.8)$ & $35(20.5)^{*}$ & $41(23.5)^{\dagger}$ \\
Parity 0 & $113(56.2)$ & $136(79.5)^{*}$ & $133(76.5)^{\dagger}$ \\
Parity 1-3 & $3(1.5)$ & $9(5.3)^{\ddagger}$ & $6(3.4)$ \\
Previous macrosomic & $42(20.9)$ & $58(34)^{*}$ & $69(39.6)^{\dagger}$ \\
Type 2 DM in first-degree relatives & not determined & $1,668 \pm 264^{\ddagger}$ & $1,584 \pm 122^{\dagger}$ \\
Diet, kcal & & & $6.1 \pm 4.4^{\dagger, \S}$ \\
At delivery & $10.3 \pm 5.4$ & $9.5 \pm 5.1$ & $37.3 \pm 3.3$ \\
Pregnancy weight gain, kg & $38.1 \pm 2.5$ & $37.4 \pm 3.5$ & $2,982 \pm 615$ \\
Gestational age, weeks & $2,877 \pm 511$ & $2,983 \pm 549$ & \\
Birth weight, g & & & \\
\hline
\end{tabular}

${ }^{\text {a }}$ Data presented as $\mathrm{n}(\%)$ or mean $\pm \mathrm{SD}$. $\mathrm{DM}=$ Diabetes mellitus.

ANOVA or $\chi^{2}:{ }^{*} \mathrm{p}<0.01 \mathrm{NW}$ vs. OW, ${ }^{\dagger} \mathrm{p}<0.001 \mathrm{NW}$ vs. OB, ${ }^{\ddagger} \mathrm{p}<0.05 \mathrm{NW}$ vs. OW, ${ }^{\S} \mathrm{p}<0.001 \mathrm{OW}$ vs. OB.

ery, stillbirth, early neonatal death, small for gestational age (SGA) or large for gestational age (LGA) (defined as $<10$ th percentile or $>90$ th percentile, respectively for sex-specific tables for the Mexican population) [14], and major congenital defects.

\section{Statistical Analysis}

Descriptive statistics, outcome frequencies, difference of proportions ( $\chi^{2}$ test or Fisher's exact test), one-way ANOVA with Bonferonni's correction test was used for differences between individual groups and multivariable logistic regression and odds ratio (OR) and 95\% CI were calculated (as indicated). The SPSS software, version 15.0 (SPSS Inc., Chicago, Ill., USA) was employed. Significance was achieved at $\mathrm{p}<0.05$.

\section{Results}

Demographic characteristics of the women and their newborns are shown in table 1. At admission, NW women were younger than $\mathrm{OW}$ and $\mathrm{OB}$ women with a lower body weight and BMI (as expected), mainly primigravid and with fewer first-degree relatives with type 2 diabetes mellitus. Total daily caloric intake was significantly lower in OB women than in OW women $(\mathrm{p}<0.05)$ and in both compared to only $22 \mathrm{NW}$ women $(1,790 \pm 141 \mathrm{kcal} /$ day, $\mathrm{p}<0.001)$ that received nutritional assessment at their first prenatal visit and thus, in the rest of NW group it was not possible to be determined. No between-group differences existed, either in gestational age at delivery, or among their newborns' birth weights. Gestational weight gain (mean $\pm \mathrm{SD})$ was lower in $\mathrm{OB}$ women $(6.1 \pm 4.4 \mathrm{~kg})$ compared to OW $(9.5 \pm 5.1 \mathrm{~kg})$ and NW $(10.3 \pm 5.4 \mathrm{~kg})$ women $(\mathrm{p}<0.001)$ without differences among the latter two groups. However, when the gestational weight gain was analyzed according to the IOM recommendations, NW women had 31.3, 51.7 and 17\%, OW women had 14, 50.3 and $35.7 \%$ and $\mathrm{OB}$ women had 20.7, 56.9 and $22.4 \%$ below, within and above, respectively, the IOM weight gain recommended. The percentage of women with a weight gain below recommended was greater in NW versus OW ( $p=0.0001)$ and versus OB $(p=0.02)$ and the percentage of $\mathrm{OW}$ women with a weight gain above recommended was greater than in NW $(\mathrm{p}=0.0001)$ and $\mathrm{OB}$ women $(\mathrm{p}<0.01)$.

Frequency and adjusted ORs (for age and parity) for maternal and newborn outcomes are presented in table 2 . Additionally, OR for GDM was adjusted for type 2 diabetes mellitus in first-degree relatives. The incidence of GDM in the whole group was $10.6 \%$. NW and OW women had a similar frequency of GDM, but lower than in $\mathrm{OB}$ women ( $p<0.001$ and $<0.01$, respectively). The incidence of preeclampsia was significantly higher in $\mathrm{OB}$ than in NW ( $<<0.01)$. The lack of spontaneous initiation of labor was the greatest in $\mathrm{OB}$ women compared to $\mathrm{OW}$ women $(\mathrm{p}<0.01)$ and NW $(\mathrm{p}<0.001)$. There were no other significant between-group differences in any other maternal outcomes. 
Table 2. Number (\%) and odds ratios (OR) adjusted for age and parity with $95 \%$ confidence intervals for maternal and newborns outcomes

\begin{tabular}{|c|c|c|c|}
\hline Outcome & $\begin{array}{l}\text { Normal weight }(\mathrm{n}=201) / \\
\text { basal risk }\end{array}$ & $\begin{array}{l}\text { Overweight }(\mathrm{n}=171) / \\
\text { adjusted OR }\end{array}$ & $\begin{array}{l}\text { Obesity }(\mathrm{n}=174) / \\
\text { adjusted OR }\end{array}$ \\
\hline Miscarriages & $\begin{array}{l}10(4.9) / \\
1\end{array}$ & $\begin{array}{c}6(3.5) / \\
0.56(0.19-1.6)\end{array}$ & $\begin{array}{c}10(5.7) / \\
0.90(0.35-2.3)\end{array}$ \\
\hline Gestational diabetes mellitus & $\begin{array}{l}10(4.9) / \\
1\end{array}$ & $\begin{array}{l}14(8.1) / \\
1.1(0.47-2.8)\end{array}$ & $\begin{array}{l}34(19.5)^{*}+\dagger \\
4.2(1.9-9.3)\end{array}$ \\
\hline Preterm delivery & $\begin{array}{c}33(16.4) / \\
1\end{array}$ & $\begin{array}{c}33(19.2) / \\
1.11(0.63-1.94)\end{array}$ & $\begin{array}{c}34(19.5) / \\
1.05(0.59-1.8)\end{array}$ \\
\hline Premature rupture of membranes & $\begin{array}{l}10(4.9) / \\
1\end{array}$ & $\begin{array}{c}8(4.6) / \\
0.65(0.23-1.7)\end{array}$ & $\begin{array}{c}11(6.3) / \\
0.85(0.33-2.1)\end{array}$ \\
\hline Gestational hypertension & $\begin{array}{l}4(1.99) / \\
1\end{array}$ & $\begin{array}{c}8(4.67) / \\
2.9(0.82-10.4)\end{array}$ & $\begin{array}{c}6(3.4) / \\
2.2(0.57-8.9)\end{array}$ \\
\hline Preeclampsia & $\begin{array}{l}8(3.98) / \\
1\end{array}$ & $\begin{array}{l}10(5.84) / \\
2.0(0.73-5.4)\end{array}$ & $\begin{array}{l}16(9.2)^{*} / \\
3.3(1.2-8.8)\end{array}$ \\
\hline Lack of spontaneous labor & $\begin{array}{l}71(35.3) / \\
1\end{array}$ & $\begin{array}{c}81(47.3)^{\ddagger} / \\
1.49(0.96-2.31)\end{array}$ & $\begin{array}{l}55(59.1)^{*, \dagger} / \\
2.4(1.5-3.8)\end{array}$ \\
\hline Small for gestational age & $\begin{array}{c}23(11.4) / \\
1\end{array}$ & $\begin{array}{c}13(7.6) / \\
0.63(0.30-1.32)\end{array}$ & $\begin{array}{c}15(8.6) / \\
0.79(0.37-1.6)\end{array}$ \\
\hline Large for gestational age & $\begin{array}{l}11(5.7) / \\
1\end{array}$ & $\begin{array}{l}10(5.8) / \\
1.2(0.48-3.0)\end{array}$ & $\begin{array}{l}15(8.6) / \\
1.8(0.76-4.22)\end{array}$ \\
\hline
\end{tabular}

The number of stillbirths was 2, 3, 3, of major congenital malformations was 3, 5, 3 and puerperium complications was 21, 21, 16 in NW, OW and OB women, respectively, without between-group statistical differences.

No significant differences were observed either in the frequency of SGA or LGA newborns among the three groups of women. Considering newborns at term, no early neonatal deaths occurred in NW ( $\mathrm{n}=158)$, OW ( $\mathrm{n}=$ $132)$ or $\mathrm{OB}(\mathrm{n}=130)$ women.

When women with GDM were excluded, the significant differences described above between NW, OW and OB women remain similar in this group of 488 normal glucose-tolerant women (data not shown).

An independent analysis of the small number of women with GDM (table 2) did not disclose significant between-group differences in any of the maternal or newborn outcomes. There were 6 LGA babies out of 34 newborns in the $\mathrm{OB}$ group but none in the OW or NW women. Interestingly, in women with GDM the gestational weight gain was similar among the three groups (data not shown).

The mode of resolution and incidence of cesarean section (CS) was the lowest in NW women (50.7\%) compared to $\mathrm{OW}$ and $\mathrm{OB}$ women (63.2 and $74.7 \%)$, respectively $(\mathrm{p}<0.001)$ (table 3). Nevertheless, when separated according to cesarean indication, we did not find differences between the groups either in emergency or in elective CS, but there were more planned CS in the OB than in the NW $(p<0.0001)$ and OW groups $(p=0.04)$. The main indication for planned CS was two previous CS with 27.2, 40 and $51 \%$ in NW, OW and $\mathrm{OB}$ women, respectively.

\section{Discussion}

In the last two decades in México there has been a rapidly progressive increase in the incidence of women with overweight and obesity [2], a well-recognized risk factor for increased maternal, fetal and neonatal adverse outcomes [3-7, 15-17]. Thus, it is important to search for alternative medical-nutrition approaches in the management of this obstetric population aimed to decrease these body weight-related morbidities, one of the few amendable risk factors before and during pregnancy. Especially true if we consider the extra risk posed by the greater incidence of GDM in Mexican women (Hispanic) as compared to Caucasian women [9]. 
Table 3. Mode of resolution of the pregnancy and indications for cesarean section in the three groups studied

\begin{tabular}{|c|c|c|c|}
\hline Mode of resolution & $\begin{array}{l}\text { NW } \\
(n=201)\end{array}$ & $\begin{array}{l}\text { OW } \\
(\mathrm{n}=171)\end{array}$ & $\begin{array}{l}\text { OB } \\
(n=174)\end{array}$ \\
\hline \multicolumn{4}{|l|}{ Vaginal } \\
\hline Curettage & $10(5.0)$ & $6(3.5)$ & $10(5.8)$ \\
\hline Vaginal delivery & $89(44.3)$ & $57(33.3)^{*}$ & $34(19.5)^{* *, \dagger}$ \\
\hline Cesarean section & $102(50.7)$ & $108(63.2)^{*}$ & $130(74.7)^{* *}$ \\
\hline Elective & $30(14.9)$ & $29(17.0)$ & $37(21.3)$ \\
\hline Planned & $33(16.4)$ & $45(26.3)^{*}$ & $64(36.8)^{* *, \dagger}$ \\
\hline Emergency & $39(19.4)$ & $34(19.9)$ & $29(16.6)$ \\
\hline
\end{tabular}

In brief, we have observed that both $\mathrm{OW}$ and $\mathrm{OB}$ women had a greater incidence of GDM, preeclampsia and lack of spontaneous labor than NW women, but there were no significant between-group differences in emergence cesarean section, birth weight, SGA or LGA newborns or major congenital anomalies, and no early neonatal deaths occurred in any group. The same picture emerged for both maternal and neonatal outcomes when the small number of women with GDM was analyzed independently.

An important finding was that in the entire group of women the gestational weight gain (absolute or percentage) was significantly less in $\mathrm{OB}$ than in $\mathrm{OW}$ and $\mathrm{NW}$ women. In addition, $78 \%$ of $\mathrm{OB}$ women were within or below the IOM's recommendations similar to NW women, but greater than OW women, perhaps as the result of incomplete adherence to nutritional recommendations [18] or to the lower caloric intake in OB than in OW women. Furthermore, the absolute gestational weight gain in women with GDM was similar between $\mathrm{OB}$, OW and $\mathrm{NW}$ women which is in accordance with previous studies showing that prepregnancy weight, but not pregnancy weight gain was strongly associated with GDM $[19,20]$. In this small group of glucose-intolerant women, the presence of GDM did not represent any additional risk for adverse outcomes compared to the larger group of glucose-tolerant women, perhaps because they were detected early in the second trimester of gestation with a tight blood glucose control (fasting $\leq 5.3 \mathrm{mmol} / \mathrm{l}$ and $1 \mathrm{~h}$ postprandial $\leq 7.8 \mathrm{mmol} / \mathrm{l}$ ) throughout pregnancy [21]. Although the incidence of GDM was $19.5 \%$ in OB women, it was less in NW and OW women. Furthermore, the incidence of GDM in NW and OW women was lower than the incidence reported previously in Mexican women

Obesity, Prenatal Nutrition and Perinatal Outcomes
[22]. Others have reported an OR for GDM of 5.2 and 2.4 in $\mathrm{OB}$ and $\mathrm{OW}$ Caucasian women, respectively [3], similar to ours.

The incidence for preeclampsia in $\mathrm{OB}$ women was similar to previous reports $[3,7,15,17]$ but not for gestational hypertension either in $\mathrm{OB}$ or in $\mathrm{OW}$ women, perhaps due to the limited statistical power for this outcome.

We did not find an increased frequency in other previously reported adverse outcomes in $\mathrm{OB}$ and OW women [3-7, 23-25].

The whole incidence of cesarean deliveries in OW and $\mathrm{OB}$ women was equally increased as in previous studies $[3,6,17,24]$. This higher rate in our study is likely to be at least partially influenced by in-house obstetric practice, with a high incidence of elective cesarean section, but we neither found between-group differences in emergency cesarean nor in labor or puerperium complications. This observation is at variance with previous reports $[3,24,25]$ describing a greater risk for the use of forceps, shoulder dystocia, early neonatal death, endometritis and wound infection in $\mathrm{OB}$ women [3, 4, 23-25]. This difference can be best explained by our lower incidence of LGA newborns, the high rate of cesarean deliveries and the routine use of prophylactic antibiotics.

The OW and OB women (with and without GDM) did not have an increased risk for macrosomic or LGA newborns as reported by others [3,24], most likely due to the rigorous control of gestational weight gain, the early detection of GDM and the sustained strict blood glucose control throughout their pregnancies.

Our study has several limitations such as the relatively small sample size; it is an observational study, our results are specific for Mexican women living in low- and middle-class urban areas with excessive intake of saturated 
fats and refined carbohydrates [26], and it is not a randomized clinical trial. However, the inclusion of a control group, i.e. OW and $\mathrm{OB}$ pregnant women without any nutrition assessment, would imply an ethical issue, since obesity has long been recognized as a risk factor increasing pregnancy-associated morbidity and over the last two decades all nondiabetic $\mathrm{OW}$ and $\mathrm{OB}$ pregnant women attending our institution receive nutrition assessment from their first prenatal visit until the end of pregnancy.

Finally, the present results suggest that an early (first trimester) intensive and sustained obstetric-nutrition prenatal care, including universal screening for GDM in $\mathrm{OB}$ and $\mathrm{OW}$ women, may contribute to a noticeable decrease on maternal and newborn adverse outcomes, except in the risk for GDM, preeclampsia and lack of spontaneous labor. Considering race/ethnic, demographic, and nutritional similarities between Mexican urban lowand middle-class pregnant women and other Latin American pregnant women, after proper validation with randomized clinical trials, our results could have medical relevance to other areas of México and likely to some Latin American countries facing a rapidly increasing incidence of obesity. In these countries, few people will benefit from today's technological advances in the medical treatment of diabetes and it is unlikely that a 'glucocen- tric' treatment could be the only solution for better maternal and perinatal outcomes, at least in developing countries [27]. Recently, it has been suggested that the more beneficial effects of the control of gestational weight gain in pregnancy outcomes depend on the woman's prepregnancy BMI $[28,29]$. Thus, $\mathrm{OW}$ and $\mathrm{OB}$ women should become a key prepregnancy target aiming to decrease the gestational body weight-associated morbidities, since they represent one of the few amendable risk factors before and during pregnancy. More research in lifestyle interventions (medical nutrition therapy and physical activity) is primordial to prevent maternal and newborn complications in obese and overweight women.

\section{Acknowledgement}

The costs of publication of this article were covered with funding from CONACYT record No. (391) 212250-42101, agreement No. 0151819.

\section{Disclosure Statement}

None of the authors have any conflict of interest to declare.

\section{References}

1 World Health Organization: Obesity and overweight. WHO 2006 Fact sheet No. 311. http://www.who.int/mediacentre/factsheets/fs311/en/index.html

2 Olaiz-Fernández G, Rivera-Dommarco J, Shamah-Levy T, Rojas R, VillalpandoHernández S, Hernández-Ávila M, Sepúlveda-Amor J: National Health and Nutrition Survey. Cuernavaca, Instituto Nacional de Salud Pública, 2006.

-3 Baeten JM, Bukusi EA, Lambe M: Pregnancy complications and outcomes among overweight and obese nulliparous women. Am J Public Health 2001;91:436-440.

4 Usha Kiran TS, Hemmadi S, Bethel J, Evans $\mathrm{J}$ : Outcome of pregnancy in a woman with an increased body mass index. BJOG 2005;112: 768-772.

5 Hedderson MM, Williams MA, Holt VL, Weiss NS, Ferrara A: Body mass index and weight gain prior to pregnancy and risk of gestational diabetes mellitus. Am J Obstet Gynecol 2008;198:409.e1-e7.

-6 Burstein E, Levy A, Mazor M, Wiznitzer A, Sheiner E: Pregnancy outcome among obese women: a prospective study. Am J Perinatol 2008;25:561-566.
Fortner RT, Pekow P, Solomon C, Markenson G, Chasan-Taber L: Prepregnancy body mass index, gestational weight gain, and risk of hypertensive pregnancy among Latina women. Am J Obstet Gynecol 2009;200:167. e1-7.

-8 Perichart-Perera O, Balas-Nakash M, ParraCovarrubias A, Rodríguez-Cano A, Ramírez-Torres A, Ortega-González C, Vadillo-Ortega F: A medical nutrition therapy program improves perinatal outcomes in Mexican pregnant women with gestational diabetes and type 2 diabetes mellitus. Diabetes Educ 2009;35:1004-1013.

\9 Yogev Y, Langer O, Xenakis E, Rosenn B: Glucose screening in Mexican-American women. Obstet Gynecol 2004;103:12411245.

10 Institute of Medicine of the National Academies: Weight Gain during Pregnancy: ReExamining the Guidelines. Report brief. Washington, 2009. http://www.iom.edu/Reports.aspx

11 Arroyo P, Casanueva E, Reynoso M: Expected body weight for height and gestational age: reference tables. Ginecol Obstet Mex $1985 ; 53: 227-231$.
12 American Diabetes Association: Gestational diabetes mellitus (position statement). Diabetes Care 2004;27(suppl 1):S88-S90.

13 ACOG Practice Bulletin: Diagnosis and management of preeclampsia and eclampsia. Obstet Gynecol 2002;99:159-167.

14 Jurado-García E, Abarca-Arroyo A, OsorioRoldán C, Campos-Ordaz R, SaavedraMújica A, Álvarez-De los Cobos J, Parra-Jiménez S: Intrauterine growth: fetal body weight and length in México City. Bol Med Hosp Infant Mex 1970;27:163-195.

15 O'Brien TE, Ray JG, Chan WS: Maternal body mass index and the risk of preeclampsia: a systematic overview. Epidemiology 2003;14:368-374.

16 Chu SY, Kim SY, Lau J, Schmid CH: Maternal obesity and risk of stillbirth: a meta-analysis. Am J Obstet Gynecol 2007;197:223-228.

17 Owens LA, O'Sullivan EP, Kirwan B, Avalos G, Gaffney G, Dunne F, ATLANTIC DIP Collaborators: The impact of obesity on pregnancy outcome in glucose tolerant women. Diabetes Care 2010;33:577-579. 
18 Della Líbera B, Ribeiro-Baião M, de SouzaSantos MM, Padilha P, Dutra-Alves P, Saunders C: Adherence of pregnant women to dietary counseling and adequacy of total gestational weight gain. Nutr Hosp 2011;26: 79-85.

19 Herring SJ, Oken E, Rifas-Shiman SL, RichEdwards JW, Stuebe AM, Kleinman KP, Gillman MW: Weight gain in pregnancy and risk of maternal hyperglycemia. Am J Obstet Gynecol 2009;201:61.e1-e7.

20 Saldana TM, Siega-Riz AM, Adair LS, Suchindran C: The relationship between pregnancy weight gain and glucose tolerance status among black and white women in central North Carolina. Am J Obstet Gynecol 2006;195:1629-1635.
21 Jovanovic L, Pettitt DJ: Treatment with insulin and its analogs in pregnancies complicated by diabetes. Diabetes Care 2007;30(suppl 2):S220-S224.

22 Espinosa de los Monteros A, Parra A, Hidalgo $\mathrm{R}$, Zambrana $\mathrm{M}$ : The after breakfast 50g,1-hour glucose challenge test in urban Mexican pregnant women: its sensitivity and specificity evaluated by three diagnostic criteria for gestational diabetes mellitus. Acta Obstet Gynecol Scand 1999;78:294-298.

23 Kristensen J, Vestergaard M, Wisborg K, Kesmodel U, Secher NJ: Pre-pregnancy weight and the risk of stillbirth and neonatal death. BJOG 2005;112:403-408.

24 Lynch CM, Sexton DJ, Hession M: Obesity and mode of delivery in primigravid and multigravid women. Am J Perinatol 2008;25: 163-168.

25 Myles TD, Gooch J, Santoloya J: Obesity as an independent risk factor for infectious morbidity in patients who undergo cesarean delivery. Obstet Gynecol 2002;100:959-964.
26 Ortega-González C, Ballesteros A, Casanueva E, Fonseca T, Casique E, Parra A: Searching for alternative methods of diagnosing gestational diabetes mellitus in a Mexican urban population. Med Sci Monit 2008; 14 : 598-603.

27 Editorial: Type 2 diabetes time to change our approach. Lancet 2010;375:2193.

28 Crane JM, White J, Murphy P, Burrage L, Hutchens D: The effect of gestational weight gain by body mass index on maternal and neonatal outcomes. J Obstet Gynaecol Can 2009;31:28-35.

29 Choi SK, Park IY, Shin JC: The effects of prepregnancy body mass index and gestational weight gain on perinatal outcomes in Korean women: a retrospective cohort study. Reprod Biol Endocrinol 2011;9:6. 